\title{
Reflejos museográficos de una política colonizadora: la provincia de Valdivia en la Exposición de Artes e Industria de Santiago de Chile, 1872
}

\author{
Danilo Duarte \\ Maestría en Historia, Universidad del Valle, Colombia \\ danilo.duarte@correounivalle.edu.com
}

Resumen Con dos propósitos en mente, el artículo analiza la colección que la provincia de Valdivia envió a la Exposición de Artes e Industria realizada en Santiago de Chile en 1872. En primer lugar, intenta demostrar que fueron los efectos de la política de colonización los que habilitaron una diferenciación entre las colecciones enviadas por esta provincia y otras exhibidas por sus pares del centro, norte y extremo sur del país. Por otro, se afirma que aunque es una colección que podría representar el proyecto civilizador de una élite económica, industrial e intelectual local, en el escenario de la exposición de Santiago transmuta en proyecto nacionalista, con lo cual se contribuye a la consolidación de un imaginario común.

Palabras claves: Colonización alemana, ciencia, industria, arte, colección.

$* * *$

\section{Introducción}

Este artículo estudia la participación de la provincia deValdivia en la Exposición de Artes e Industria realizada en la ciudad de Santiago de Chile durante las fiestas patrias de septiembre de 1872, a partir de la colección de objetos que el jefe de gobierno de esa provincia envió al evento, y otros más remitidos por particulares para el mismo efecto. Con ello se intenta demostrar que fueron los efectos de la política de colonización los que permitieron la distinción entre las colecciones enviadas por la provincia de Valdivia y las presentadas por otros entes administrativos del centro, norte y extremo sur del país; diferenciación que va más 
allá de los productos naturales típicos que, como zonas geográficas específicas, pudieron haber presentado en esa exhibición. De igual forma, se afirma que aunque es una colección que se podría interpretar como representativa del proyecto civilizador de una élite local, en el escenario de la exposición de Santiago transmuta en proyecto nacionalista. De esta manera, la exhibición en su totalidad contribuye a la construcción de una memoria museográfica nacional. Para demostrar lo anterior, se recurre a documentación primaria (publicaciones oficiales y diarios de la época) y fuentes secundarias (artículos y capítulos de libros) con las cuales se reconstruye el contexto historiográfico de la provincia y se asocia la colección enviada al evento con científicos, artistas e industriales locales alemanes residentes en la provincia de Valdivia.

Si bien es cierto que la colonización alemana del sur de Chile ha sido y sigue siendo ampliamente estudiada, también lo es que el abordaje de la formación de colecciones iniciadas por migrantes llegados a esas tierras es una tarea pendiente, aunque ya se están dando pasos importantes para avanzar al efecto con trabajos afines publicados recientemente.

\section{El contexto}

Fundada como fuerte español en 1543, la ciudad de Valdivia, en el sur de Chile, fue uno de los últimos bastiones que el ejército realista defendió hasta abandonar definitivamente territorio chileno en 1820. Para llegar a ser lo que es hoy, los inicios de Valdivia como ciudad republicana no fueron particularmente fáciles. Luego de las Guerras de Independencia, la provincia quedó abandonada poco menos que a su suerte: un porcentaje importante de la élite local migró a la capital, mientras que la restante orientada hacia los cargos públicos y el comercio minorista, no disponía de la voluntad ni de los medios para sacar a la provincia del estancamiento en el que se encontraba, en tanto que las autoridades locales escribían a la capital solicitando la construcción de infraestructura pública. Si a lo anterior se agrega la escasa población con la que contaba la provincia, el exiguo, por no decir nulo capital para el emprendimiento, se puede concluir sin dificultad que el horizonte cercano de la provincia se avizoraba poco auspicioso. Esta lejanía de la mano del gobierno central podría explicarse a partir del lugar que ocupó esa misma élite durante las guerras independentistas, a favor del régimen monárquico. Así, luego de la retirada de los españoles, el gobierno central poco intervino cuando se trató del financiamiento de la administración local, lo que redundó en un proceso continuado de crisis económica; aunado "el desprecio de los grupos dirigentes por la realidad zonal y el envío masivo de expulsados de la zona central" (Muñoz, 2008, p. 25), podría decirse que Santiago estaba haciendo pagar a esta región por haberse mantenido del lado del enemigo (Bernedo, 1999; Muñoz, 2008; Quezada, 2009).

Existe un relativo consenso al afirmar que la situación de la provincia cambió con la llegada de los primeros colonos a la región. Aunque esfuerzos por poblar los territorios 
nacionales se venían realizando con antelación, no fue sino hasta la publicación de la así llamada ley de inmigración selectiva, del 18 de noviembre de 1845, cuando un esfuerzo sistemático del Estado dio como resultado el desembarco de una población teutona con un perfil particular: además de artesanos y agricultores desembarcaron en el puerto de Valdivia comerciantes, funcionarios e intelectuales, en algunos casos, con el capital suficiente para impulsar algún tipo de industria. El conjunto conformaba las huestes que llevarían el progreso a esta zona del país, misma población que se podría clasificar en tres clases, según los tipos de agentes que propiciaron su arribo a la zona, a saber: los llevados por cuenta del Estado, los enganchados por particulares y los que migraron de forma espontánea (Izquierdo, 2008). En efecto, entre 1850 y 1875, unos 6.000 alemanes se instalaron en el sur de Chile de los cuales 2.800, aproximadamente, lo hicieron en la ciudad de Valdivia y sus zonas aledañas, de ese número una parte fundó una serie de fábricas cerveceras, de curtiembres, de alcoholes, que a la postre, inaugurarían una etapa económica de "expansión en dependencia" que posicionó a la región como un modelo de crecimiento y desarrollo distinto al de otras regiones, permitiéndole a la provincia mantenerse ajena a las crisis económicas vividas por el resto del país; aunque dependiente en el sentido de la fuerte injerencia que los recursos extranjeros y los contactos comerciales foráneos tuvieron en el desarrollo de dicha fase económica (Bernedo, 1999; Ojeda, 1980). Investigaciones recientes comparten la opinión acerca de la importancia que la migración germana tuvo para el desarrollo socioeconómico, científico y cultural, tanto a nivel local como nacional, aunque también le han prestado atención a la "gente menuda", es decir, la población mayoritaria, y la manera en que ella se vio afectada por dicha inmigración y cómo enfrentó los cambios acaecidos en la estructura de la sociedad provincial producto de esta misma.

Dicha ley regulaba la ocupación de alrededor de seis mil cuadras ${ }^{1}$ de terrenos baldíos en propiedad del Estado chileno para que se pudieran instalar allí colonias de naturales y extranjeros, siempre y cuando esos grupos se comprometieran a ejercer alguna industria útil en beneficio del país. Si ese era el caso, el gobierno se hacía cargo de asignar cierto territorio cuyas dimensiones variarían según la ubicación geográfica de la colonia: si ésta se encontraba entre la zona comprendida entre los ríos Copiapó por el norte y Biobío por el sur, la asignación por familia no podía exceder las ocho cuadras de terreno por cada padre de familia, a las que se le agregaban cuatro más por cada hijo mayor de catorce años de edad. En el caso en que el asentamiento se encontrará al norte del río Copiapó y al sur del Biobío, esta asignación aumentaría a veinticinco cuadras por cada padre de familia y a doce por cada hijo mayor de diez años. Además, con cargo al tesoro público, los colonos serían trasladados al punto de residencia definitiva y recibirían por parte del Estado semillas y herramientas para poder cultivar la tierra y mantenerse durante el primer año de estadía, junto a ello, los colonos de las zonas extremas, o sea, los ubicados

1 La cuadra es una unidad de área equivalente a $6.400 \mathrm{~m}^{2}$ aproximadamente. 
al norte del río Copiapó y al sur del Biobío estarían exentos de pagar durante veinte años las contribuciones de diezmo, catastro, alcabala y patente (Anguita; Quesney, 1902).

Aunque la implementación de esta ley en las tierras valdivianas fue menos armónica de lo que se lee en el escrito y no estuvo exenta de conflicto. La publicación de la ley de inmigración de 1845 provocó una especulación respecto a la cantidad de colonos que llegarían a la provincia, impulsando una rápida compra de los terrenos públicos cercanos a la villa de Valdivia. Como consecuencia de ese proceso de especulación de la tierra, a la llegada de los primeros inmigrantes paradójicamente no existían terrenos públicos para su asentamiento dentro del Departamento de Valdivia (Muñoz, 2008), o si había eran de muy mala calidad y las tierras particulares disponibles habían aumentado su valor en un 100\%, muchas de las cuales, además, eran verdaderos pantanos (Quezada, 2009). En este sentido, se observan a lo menos dos procesos que subyacen a esta dinámica migratoria: la especulación de terrenos públicos que trajo consigo su concentración en manos de unos pocos dueños y, como consecuencia, el desplazamiento de sus antiguos ocupantes, y el cambio de la vocación productiva del suelo que produjo la migración campesina hacia nuevos núcleos urbanos como Valdivia, que de villa administrativa pasó a convertirse lentamente en un centro social y comercial altamente segregado en términos políticos, sociales y urbanos. Además, la misma estrategia de provisión de tierras por parte del Estado para implementar esta política resultaba particularmente conflictiva, ya que la década de 1840 inauguró un periodo que se caracterizó por el progresivo aumento de las tierras en manos del Estado a costa de la expropiación de tierras comunitarias de la población indígena, lo que provocó su desalojo desde sus propios territorios hacia la zona costera, y por ende, el vaciamiento de la zona central de población mapuche que, en conjunto con las misiones religiosas presentes en la zona, representaban para el gobierno central verdaderos "focos de resistencia frente a las políticas estatales" (Muñoz, 2008, p. 36).

La "gente menuda", como el campesinado, también se vio afectada por esta política de colonización. Al estar viviendo en los terrenos de las comunidades religiosas fueron expulsados de éstos para venderse o entregarse a los colonos, fenómeno que también tuvo lugar en las zonas cercanas a la ciudad de Valdivia; convirtiéndose en una "masa trashumante" que al emigrar a la naciente urbe en búsqueda de nuevas formas de subsistencia terminó, en parte, reconvirtiéndose hacia la delincuencia: el abigeato y el robo a personas y de especies (Muñoz, 2008). Pudiendo haber sido empleada en los emprendimientos agrícolas fomentados por los nuevos colonos, la mano de obra trashumantes de campesinos desplazados fue apartada por otra proveniente de la isla de Chiloé más al sur, por chilotes, y por otros empleados contratados directamente en Alemania por los emprendedores germanos: campesinos alemanes. He aquí una "falla fundamental" de esa ley: los colonos debían llegar a Chile para potenciar la industria nacional y no la agricultura, sin mencionar que los campesinos alemanes contratados no formaban parte de la ley de inmigración (Muñoz, 2008). Aunque esta afirmación respecto a una supuesta fisura en la política habría que matizarla con la hipótesis de Quezada, para quien el resurgir económico de Valdivia se sostiene en "la llegada de los 
inmigrantes alemanes y las escasas oportunidades agrícolas que les entregó la tierra y el medio geográfico" (Quezada, 2009, p. 122), ya que al no poder cumplir las expectativas agrícolas por las que habían migrado, se volvieron sobre sus antiguos oficios (intelectuales, manuales y comerciales) produciendo una reactivación económica que daría paso a la industrialización de Valdivia. El de tendero podría ser uno de esos oficios. Para Muñoz, los alemanes supieron comprender la dinámica económica de la región centrada en el intercambio entre la zona de la Araucanía y la pampa argentina, entre las poblaciones rurales, indígenas y las villas, por ello que varios optaron por este oficio, lo que provocó que diversificaran su ámbito productivo hacia la agro-industria dominando en poco tiempo los tres pilares de la economía regional: la producción de alcoholes, curtiembres y harinas (Muñoz, 2008). En síntesis, se tiene que los alemanes reinstalados en la emergente ciudad desarrollaron sus oficios e invirtieron su capital en pequeños negocios, que darán paso luego a las sociedades comerciales y éstas a las grandes industrias, no sin haber generado graves consecuencias para las poblaciones nativas (Quezada, 2009).

En las memorias sobre la colonización de Valdivia, el Agente de Colonización Vicente Pérez Rosales destacaba las producciones naturales y artificiales de la provincia. Para el momento en el que el funcionario escribe, 1852, el departamento de Valdivia era el más pobre de los tres que constituían la provincia del mismo nombre en lo que se refería a producción agrícola, sin embargo, esperaba que conforme se fuera consolidando el poblado de San José, creado en 1850, distante 50 kilómetros al Noreste de la ciudad de Valdivia, los productos de la región despuntarían, destronando del mercado local a los producidos en Osorno y en La Unión. En las páginas de su informe podría decirse que Pérez ordena la situación de la provincia en tres tiempos reflejados en las ideas sobre lo que ésta venía siendo (productos naturales), lo que era (artes rurales/industria rudimentaria) y lo que podría llegar a alcanzar: la industria plena. Entre los productos naturales vegetales destacaba las maderas extraídas de las profundidades de los densos bosques valdivianos que se podrían catalogar según su destino: para la construcción naviera y de viviendas, para la construcción en general y para la industria del mueble y de obra fina. Realzaba también las extensiones de pastizales para el ganado. Dentro de los productos minerales, el carbón piedra y las arcillas que, por su variedad y adaptabilidad para toda clase de trabajos de alfarería y fabricación de ladrillos y de crisoles, deberían en algún momento significar beneficios financieros. Respecto a los productos naturales del reino animal, el funcionario destacaba por sobre la supuesta carestía de animales terrestres, abundancia de peces, aves acuáticas y lobos marinos, estos últimos, a la espera de la explotación industrial de su cuero y aceite, ramo que debía dirigirse al mercado externo ya que dichos productos eran poco apreciados por lo pescadores locales (Pérez, 1852).

A siete años de haberse firmado la ley de colonias de naturales y extranjeros, Pérez Rosales se lamentaba de las "pocas, poquísimas" producciones de la industria local. Aunque el comercio de las maderas labradas era uno de los negocios más importantes del departamento, no se contaba con una infraestructura adecuada para desarrollarlo, ni buenos aserraderos ni almacenes donde acopiar y encontrar secos los maderos que eran 
demandados para la construcción naval. Hasta ese momento, las maderas especiales para ese rubro (ciprés, lingue, ulmo, coigüe y pellín) se obtenían cuando se necesitaban, lo que les había generado, según Pérez, un descrédito inmerecido, ya que al utilizarse todavía verdes, les era imposible ganar la consistencia y la durabilidad que la industria naviera exigía. De ahí la necesidad de bodegas para su maduración comercial. Frente a la escasez de remolques a vapor que prestaran servicio regular al comercio maderero entre los ríos y el puerto de Valdivia, el agente proyectaba una cuadra de naves para ese propósito, lo mismo que una fundición de cobre que debía instalarse en unas playas hacia el norte del puerto. En cambio, proliferaba el rubro de las "artes rurales" dedicadas principalmente a la producción de quesos y mantequillas y uno que otro molino harinero. Aunque en el ámbito de las carnes, los cueros y la curtiembre, la situación era un poco diferente. El clima de la zona, altamente lluvioso y con abundante humedad relativa, podía favorecer la industria de la salazón de carne destinada al rubro marino, aunque su mercado como tal no se había constituido todavía. Estrechamente ligado al mercado de las carnes se encontraba el de las curtiembres. Aunque no eran más de dos mil los cueros que se exportaban anualmente, se esperaba que llegado el momento en que hubiera un par de tenerías de primer orden, dicha cifra se incrementaría y se podría impulsar en la provincia un nuevo rubro, el de la fabricación de calzado impermeable. El asunto mejoraba con la industria porcina. Con la habilidad de los colonos alemanes para elaborar salchichones, jamones y otros productos derivados del cerdo, el parecer del agente era que en cuestión de tiempo éstos cautivaran los mercados de las provincias del norte. Algo similar ocurría con la industria de la cerveza y los licores. Antes de la inmigración extranjera, en la región se producía sidra en abundancia (chicha de manzana) que aunque no se consideraba un artículo de exportación, podría tener un lugar en el mercado de las aguas espirituosas en virtud de la calidad de la fruta y las características del clima. Para el año en el que Pérez Rosales escribe, existían en la ciudad de Valdivia tres fábricas de ginebra y otras dos más de cerveza; esta última era altamente valorada por su calidad, por lo que se esperaba que al año siguiente compitiera con las cervezas producidas en la zona norte del país.

En el marco del recuento que realiza Pérez, nos interesa destacar algunos productos naturales y protoindustriales que le permitirían a los colonos impulsar sus propios emprendimientos en tierra nacional; mismos que fueron enviados a participar en la Exposición de Artes e Industria de 1872 en representación del "progreso" de la provincia. Dentro de los productos naturales se cuentan las arcillas, las maderas, el carbón, y hacen parte de los industriales: manufacturas en cuero, materiales de construcción, alimentos procesados, alcoholes, jabones, etc. Junto con este tipo de negocios, los recién llegados se dedicaron también a especular en el mercado de la tierra a través de préstamos e hipotecas, en la industria de los astilleros y en compañías de navegación, además de crear activas asociaciones económicas dedicadas a la defensa de sus intereses.

¿Cómo es posible entender estos productos útiles de la vida cotidiana y del entorno natural de la sociedad valdiviana a la luz de las nociones de coleccionismo? Todo objeto, señala Baudrillard, cumple una de dos funciones, objetiva o subjetiva: puede ser utilizado 
para lo que fue creado, en cuyo caso cobra una función de uso (objetiva), o bien puede ser significado en la medida en que es abstraído de su función primaria para ser poseído y vuelto relativo a un sujeto (subjetiva). Respecto a este último aspecto, la colección vendría a ser la culmine de una apasionada empresa de posesión individual (Baudrillard, 1995). En esta misma línea se plantea la idea de objeto-signo (Morales, 2002). En su esfuerzo por encontrar un aspecto común en elementos tan dispares como los que se pueden llegar a observar en las más diversas colecciones del mundo, el historiador Pomian, arropado por el estructuralismo antropológico, la fenomenología y la lingüística acuñó la noción de objeto semióforo. Pomian plantea que textos, imágenes, insignias, objetos, sonidos, etc., incluso personas, se componen de un soporte y un signo, cada uno tiene una cara material y una cara significante, y por ende, todos potencialmente pueden llegar a ser "objetos" cargados de significaciones, productores de sentido, aunque para ello primero deben recorrer el complejo proceso de descontextualización y exposición pública, momento en que todas las propiedades visibles del objeto se convierten en signos; dinámica in vitro que al centrar la atención en dicho objeto convierte al sujeto en mero espectador del mismo. En resumen, todo "objeto sensorial" puede cobrar significado en la medida en que es exhibido y sometido a la mirada pública, cualidad que permanecerá mientras dicho objeto se mantenga activo en esa dinámica expositiva (Pomian, 1994; 1999).

Dentro de este marco conceptual, los objetos enviados a la exposición de Santiago como planos, mapas, maquetas, pinturas, grabados, composiciones musicales, maderas, máquinas a vapor y toda clase de obras, están allí nada más que para significar y crear sentido. En efecto, la trilladora en ese momento no ciega el trigo, los embutidos y salchichones no son devorados, ni los mapas señalan ya un camino cierto, todos por el momento se encuentran fuera del circuito comercial (Pomian, 1994), todos esos objetos, por específicas circunstancias históricas, actúan allí como representaciones (Morales, 2000) ¿Se pueden concebir todos estos productos naturales y artificiales como objetos de una colección? Efectivamente, porque según algunas definiciones éstos se pueden ver como un conjunto, arreglo o acumulación ordenada de cosas reunidas por un individuo o establecimiento, y porque además de agenciarse unos a otros (Faba, 2015) y referenciar luego a su creador - en ese proceso Baudrillard concibe a la colección como un sistema de objetos -, para su constitución han tenido que pasar por un proceso selectivo previo en el que dichos "productos" fueron valorados a partir de sus cualidades simbólicas, estéticas y tecnológicas. Desde esta perspectiva, subyace a la formación de cualquier tipo de colección una concepción racional del mundo que "presupone una organización subjetiva de aquellos elementos considerados significativos para un saber y una comunidad de científicos" (Morales, 2000, p. 154), cuyo estudio cobra relevancia en la medida en que en su constitución participa la mirada que circula en la esfera pública, pues es allí donde alcanza el apogeo de su significación (Morales, 2006). Precisamente, esta intencionalidad es la que a decir de Morales convierte al coleccionismo en materia de estudio de la historia, sobre todo si éste se ocupa de la doble operación que articula el relato museográfico: la organización de la recolección de objetos a partir de un paradigma dominante y la 
proyección de los valores asociados generalmente a esa misma noción (Morales, 2000). Resumiendo lo anteriormente dicho, una colección se podría conceptualizar como "una serie de objetos naturales y artificiales, mantenidos temporal o permanentemente fuera de los circuitos comerciales, a los que se les ofrece protección especial en espacios cerrados adaptados específicamente para tales propósitos y montados para su exhibición" (Pomian, 1994, p. 162).

\section{Una colección alemana de estirpe chilena: La Provincia de Valvidia en la exposición de artes e industria de 1872}

Al poco tiempo de asumir el gobierno de la provincia de Santiago, el político liberal Benjamín Vicuña Mackenna promulgó un decreto en el que mandataba, en el marco de las fiestas patrias de septiembre, la realización de una exposición de artes e industrias en la capital. Ese decreto, emitido el 5 de junio de 1872, bien podría interpretarse como el manifiesto museológico del Intendente, ya que allí el también historiador concebía a las exposiciones como los medios más efectivos para transmitir tanto al exterior como a nivel nacional una idea del progreso que había logrado Chile en poco más de medio siglo de vida independiente. Además, señalaba el decreto, la realización de este tipo de eventos daba cuenta del grado de cultura que se había logrado en el país y servía como símbolo no solo del progreso nacional sino que de unión entre todas las naciones civilizadas, en directa alusión a los países de las metrópolis (Exposición Nacional de Artes e Industria, 1873).

Para el momento en que tiene lugar la exposición, el concepto de progreso podía resumirse en el ideal de un avance permanente de la humanidad en su lucha por el perfeccionamiento moral, espiritual y material de ella misma. Aunque era una noción que tenía más de 2000 años de antigüedad, y que había adquirido múltiples significados a través de la historia, su sentido fundamental remitía, para el momento, a la constante expansión del conocimiento, las instituciones libres y la creatividad del ser humano; al avance del conocimiento, aunque especialmente referido al conocimiento práctico contenido en las artes y las ciencias. A juicio del sociólogo Robert Nisbet (1991), el lado oscuro de la idea de progreso emerge cuando para su consecución se alaba al poder político o cuando se vincula dicho progreso con alguna raza determinada.

Aunque la exposición de 1872 podría interpretarse como un emprendimiento comercial, que en parte lo era, también fue un espacio para la fundación de la nueva nación chilena. En una época en que los museos pasaban por "los años de prueba" (Achim, 2014), las exposiciones, las galerías, los salones y las bibliotecas se instalaban como verdaderos dispositivos disciplinarios que sintetizaban los elementos constitutivos de la nueva nacionalidad (Hernández, 2006) y que le permitía a la sociedad nacional autoconstruirse cívicamente (Bennett, 1988). Las carreras de burros, el palo encebado y los volantines de payasos, usuales en las festividades nacionales, no eran verdaderamente 
el símbolo del patriotismo nacional, había llegado el momento, decretaba Vicuña, de "dar a las fiestas cívicas de la nación su verdadero carácter que no es tan solo el de las reminiscencia de los gloriosos hechos del pasado, sino la significación del progreso i prosperidad" (Exposición Nacional de Artes e Industria, 1873, p.VII).

El decreto proponía originalmente una comisión de 100 miembros que se organizaría conforme los acuerdos a los que se llegara en su primera sesión de instalación, o sea, por secciones a partir de los núcleos temáticos que abordaría la exposición, cada una de ellas, a su vez, dividida en subgrupos: Sección I, Bellas Artes; Sección II, Industria Fabril; Sección III, Industria Agrícola y Sección IV, Industria Minera. Además de esa organización, en dicha sesión se definirían también los premios y los mecanismos para aceptar o rechazar los objetos enviados al evento, entre otros temas, tales como la redacción del programa general. En reuniones posteriores del directorio de la exposición liderado por una mesa directiva, en la que el intelectual e inmigrante alemán Rodulfo Amando Philippi servía como vicepresidente, secundada por una comisión formada por los presidentes, vicepresidentes y secretarios de los distintos subgrupos, se acordó convocar a todas las provincias del país para que enviaran al evento "Todo objeto de arte o industria digno de ser exhibido" (La República, 21/6/1872). En ese momento la iniciativa de un gobernante provincial pasó a constituirse en una oportunidad para forjar un proyecto nacional de autorepresentación.

Pese a tal oportunidad dada a las provincias para participar en el evento, la respuesta obtenida fue desigual. Mientras que algunos Gobernadores e Intendentes comunicaban las actividades que llevarían a cabo para alentar las tareas de recolección en el departamento o provincia a su cargo, las respuestas a esas acciones no fueron las esperadas. Hacia la zona norte de Santiago, en el departamento de Ovalle, provincia de Coquimbo, la escasa lluvia había mermado el entusiasmo de los hacendados para enviar algún tipo de producto al evento, por lo que anunciaban que mandarían solo muestras minerales que se remitirían con el nombre del mineral y su clasificación científica (El Ferrocarril, 21/8/1872). En provincias del centro sur, como la de Talca, la respuesta fue similar. Los industriales, argumentando el poco tiempo transcurrido entre la convocatoria y la inauguración del evento, poco más de tres meses, "se negaron a ejecutar obra alguna, que fuese destinada a la exposición" (El Ferrocarril, 28/8/1972); de parte de los agricultores, el argumento iba en la misma línea, lo avanzado de la época en que se lanzó la convocatoria había "impedido reunir productos de la industria agrícola que fuesen dignos de ser remitidos" (El Ferrocarril, 28/8/1972) y en otros casos, como el del departamento de Parral, en la provincia del Maule, a pesar de contar con tupidos bosques en sus territorios para enviar colecciones de maderas, los dueños de las haciendas en las que se encontraban contestaban que no les había sido posible prepararlas con tiempo (El Ferrocarril, 27/8/1872).

Aunque tales negativas no eran generalizadas. El departamento de Illapel en la misma provincia de Coquimbo, anunciaba que enviaría al evento muestras minerales, vinos y una colección de yerbas medicinales acompañadas de una etiqueta descriptiva de sus usos, escrita a partir de los conocimientos tradicionales de las mujeres yerbateras de la zona (La República, 30/8/1872); lo mismo que el departamento de Cauquenes en 
la provincia del Maule, cuyo gobernador, en nombre del departamento, enviaba cuatro colecciones de madera representativas de sus bosques (El Ferrocarril, 31/8/1872). La colonia de Punta Arenas, en el estrecho de Magallanes, remitía con cargo a la Intendencia de la capital, once bultos que contenían papas, sal, guano, carbón, pieles de guanaco, avestruz, nutria y león marino; frascos con oro y otros conteniendo cebada y "diversos artículos de los antropófagos de la tierra del fuego", que luego serían donados al Museo Nacional; vistas fotográficas de la colonia y un trozo de madera de un árbol común en la zona que, desde su base hasta donde comenzaban las primeras ramas, podía medir 20 metros (El Ferrocarril, 29/8/1872). El Intendente de la provincia de Valdivia Miguel Irarrázabal, entre tanto, remitía a Santiago, en el velero Biobío que realizaba el cabotaje Corral-Valparaíso, una colección compuesta por productos agrícolas, minerales y de las artes e industria local: cebadas, lentejas, miel de abejas, capullos de gusanos de seda, carbón piedra, jamones, salchichones, distintas clases de jabones de olor, ladrillos, productos de alfarería, trabajos de zapatería, aguardientes, un costurero elaborado con más de quince tipos de maderas de la zona, un par de ganchos para colgar ropa, un modelo de fragata a escala, una colección de animales disecados, etc. (El Ferrocarril, 29/8/1872).

En el ínterin, BenjamínVicuña Mackenna, a nombre de la directiva de la exposición, solicitaba a los presidentes de las compañías de ferrocarriles y de vapores se le diera ciertas facilidades al traslado de objetos y de personas cuya intención fuera participar en la exhibición, logrando que el Ferrocarril del Sur liberara completamente del pago de fletes a los objetos enviados a la exposición (El Ferrocarril, 28/8/1872) y otorgara un $25 \%$ de descuento a los pasajeros con ese mismo destino (El Ferrocarril, 13/9/1872). Por su parte, el Ferrocarril Santiago-Valparaíso, tanto en su línea principal como en el ramal San Felipe-Las Vegas, habilitaría recorridos expresos de $1^{\circ}$ y $2^{\circ}$ clase destinados a aquellos visitantes que contaban nada más que con un día para asistir al evento (El Ferrocarril, 12/9/1872; El Ferrocarril, 13/9/1872). En cuanto a la compañía de vapores, su agente, David Sim, ofrecía una rebaja del 50\% en el pasaje a los miembros de la sociedad musical de Valdivia que viajaran al certamen (El Ferrocarril, 5/7/1872).

\section{Los industriales}

En el recuento de la colección enviada por la provincia de Valdivia, llama la atención la ausencia de la conocida cerveza Anwandter y la inclusión, en cambio, de los jabones de olor de los mismos dueños. Esa ausencia se podría explicar a partir de las instalaciones de bodegajes que la fábrica había ido construyendo en los puertos a lo largo del país durante sus primeros años de expansión, que permitía almacenar y enviar directamente desde las bodegas en el puerto deValparaíso la cerveza de exportación que participaría en el evento y que le granjearía finalmente a la fábrica una medalla de plata. Esta fábrica fue fundada en 1851 por el farmacéutico alemán Carlos Anwandter, quien luego de advertir la mala calidad de las tierras asignadas para la faena agrícola, compró otros terrenos en la ciudad 
de Valdivia, donde instaló su residencia y la fábrica, al lado del río Calle Calle, momento en que importó desde Alemania equipamiento suficiente para comenzar la producción del lúpulo. Para 1858, la fábrica, a cargo de los hijos de Anwandter, entró en otra fase de desarrollo: abrió nuevos mercados en las zonas centro y norte del país; construyó nuevas instalaciones en Valdivia para el almacenamiento de la cebada, y en distintos puertos del país, para el bodegaje del producto, y utilizó motores a vapor para la fabricación del brebaje, mejoras que permitieron no solo el aumento de la producción, sino también la demanda por insumos básicos como la cebada, el lúpulo y la corteza de lingue. A fines del siglo XIX, el abastecimiento de madera comenzó a ser un problema para los Anwandter por lo que adquirieron en las cercanías de Valdivia una hacienda de 4.500 ha que contaba con abundantes reservas de agua y extensos bosques nativos. El aumento en la demanda de esa materia prima es explicada por el historiador Patricio Bernedo como el resultado de una permanente política de modernización de las instalaciones, lo que se traducía en la incorporación regular de nuevos motores a vapor, aunque para fines del XIX la empresa gradualmente comenzó a adoptar la energía eléctrica como complemento a la del vapor (Bernedo, 1999).

La industria de los alcoholes en el departamento no despegó sino hasta la primera mitad de la década de 1860, cuando Alberto Thater fundó una destilería en la ciudad, cuyos impactos en la economía local se hicieron sentir rápidamente, en la medida que la producción de destilados precisaba de los granos de trigo que la zona podía producir. Aunque las condiciones climáticas del departamento - lluvioso y con altos índices de humedad - impedían producir un grano de calidad comparable al de la zona central del país, una calidad inferior al de dicha región no limitaba su uso para la fabricación de alcoholes, cuya producción registró un aumento de 170\% entre 1867 y 1887 . Otro aspecto que favoreció la instalación de destilerías fue la creación de industrias asociadas a la crianza de cerdos y la fabricación de cecinas. Por un lado, los desechos de la producción de alcohol como la cáscara del trigo, podían ser reutilizados para alimentar a los cerdos, mismos que eran sacrificados para la fabricación de cecinas, por esas razones era común que contiguo a las destilerías se encontraran establos de crianza y fábricas de cecinas y embutidos. Este tipo de integración de los sectores primarios y secundarios de la economía podría explicar la participación de Thater en la exposición ya no con sus conocidos aguardientes, sino que, esta vez, con jamones, salchichones, jamón deshuesado y manteca. Así como Alberto Thater, la Sociedad Schüler y Haverbeck también se decidió a enviar una selección de sus embutidos, colección que obtuvo del jurado general una mención honrosa. Otros participantes que certifican la proliferación de destilerías en la provincia son los industriales Carlos Hoffman, Rodolfo Roessell y Sebastián Werckmeister, quienes enviaron al evento sus respectivas muestras de aguardientes, aunque pareciera ser que solo el primero estuvo finalmente en él, ya que el catálogo de la exposición lo consigna participando con aguardiente anisado y aguardiente puro.

Otra de las colecciones que se enviaron al evento tiene que ver con una serie de productos manufacturados: jamones, cueros, suelas y calzado. Aunque la primera 
curtiduría en la provincia de Valdivia data de 1798, y que antes de la llegada del primer grupo de migrantes ya existían dos tenerías en la ciudad, no fue sino hasta su instalación definitiva en el departamento cuando se observó un progreso en la industria, producto de la implantación de técnicas para el aprovechamiento de la corteza de lingue en el tratamiento y fabricación de cueros de alta calidad y en el establecimiento de líneas de cabotaje marítimo entre Valdivia y los puertos de Valparaíso (1862) y Hamburgo (1872). La importancia de esta industria para la provincia se observa en la proliferación de curtiembres que se da entre las décadas de 1860 y 1880.

En 1851, el alemán Hermann Schülke fundó el primer establecimiento de este tipo en Valdivia, aunque sus inicios fueron a escala familiar (Ortega, 2005), la inversión de nuevos capitales a diez años de su creación significó un incremento en la inversión que permitió incorporar dos nuevas áreas de negocios a la empresa: una pequeña refinería de sal y un establecimiento de venta directa al público en el centro de la ciudad, comprando posteriormente varios lotes en la Isla Teja y otros potreros, estos últimos nada más que para la crianza de ganado. A fines del siglo XIX, la fábrica consumía unas 1.500 toneladas de corteza de lingue que le permitía elaborar cueros de suela, cuya mayor parte se exportaba a Alemania (Bernedo, 1999). Los hermanos Jorge y Santiago Schüler también se dedicaron a este rubro. Uno de los aspectos interesantes a destacar de estos hermanos radica en que estructuraron un sistema de producción que integraba tanto las actividades del sector primario como las del secundario, lo que era inusual en el país para la segunda parte del siglo XIX, aunque no exclusivo de ellos tal como nos los demuestra Thather y Schülke. El eje productivo de los hermanos giraba en torno a la industria de la curtiembre y la producción de suela de zapatos que se exportaba íntegra a Alemania y para lo cual se utilizaba cerca de 400 toneladas de lingue al año. Gran parte de los animales utilizados para dicha producción eran criados por ellos mismos en una hacienda que poseían en las inmediaciones de la ciudad, y eran faenados en un matadero propio, lugar donde se separaba el cuero para la tenería, la carne para fabricar cecinas y la grasa para hacer lo propio con jabón y velas. En síntesis, el complejo industrial de los Schüler abarcaba la curtiduría, el matadero, una fábrica de cecinas, una destilería de alcoholes y dos fábricas pequeñas dedicadas a la producción de jabón y velas, lo que bien podríamos describir como empresa agro-industrial (Bernedo, 1999).

En los límites de este rubro se encuentra el industrial Christian Rudloff quien, así como los Anwandter con su cerveza, tampoco aparece en el listado oficial enviado por el Intendente de Valdivia a su par en Santiago. Aunque sí aparece mencionado en el catálogo y en las memorias del evento como premiado con una medalla de bronce por los distintos tipos de calzados que presentó. Mientras que otros industriales como Teodoro Pausenberg, Mauricio Matthias, Francisco Erhempeld, José María Adriazola y Enrique Rettig enviaron al evento distintos tipos de suelas, becerros, chagríes y trabajos de zapatería (El Ferrocarril, 29/8/1872), que al parecer no fueron aceptados, puesto que sus nombres no se vuelven a repetir en el catálogo, ni en los premios, a excepción de Rettig quien por sus botas obtuvo una mención honrosa. 
Christian Rudloff había fundado en 1853 una fábrica de zapatos, pero en vista de que las tenerías estaban enfocadas en el envío de su producción al extranjero, lo que ponía en dificultades el abastecimiento de cueros para su fábrica, a mediados de la década de 1870 decidió instalar su propia curtiembre (Ortega, 2005). Para Bernedo, en los orígenes de esta curtiduría se observan las principales características de los industriales alemanes, esto es, la capacitación en los países metropolitanos de miembros del grupo familiar cercano en los métodos y técnicas más modernos para la producción de una industria en particular. En este caso, Luis Rudloff, hijo de Christian, realizó un prolongado viaje por Estados Unidos y Europa con el propósito de conocer nuevos métodos para la fabricación de zapatos y la elaboración de cueros, además de adquirir maquinaria nueva y especializada para las fábricas de calzado y de curtiembre. A mediados de la década de 1890, la familia Rudloff exportaba a Bolivia parte de su producción de zapatos, al tiempo que enviaba a Alemania buena parte del excedente de suelas sobrantes de la producción de calzado, no obstante, el mercado nacional seguía siendo su mayor cliente: en el norte con los mineros de las oficinas salitreras y en la Tierra del Fuego, con los lavadores de oro. Para fines del siglo XIX, la curtiduría Rudloff utilizaba maquinaria a vapor que consumía alrededor de 800 toneladas de lingue al año, el insumo común de la industria.

La reiterada mención a las cantidades de cortezas de lingue explotadas y utilizadas en la producción industrial de suela tiene su explicación. La magnitud de los bosques sureños, en especial los valdivianos, hacía que se los viera como un recurso inagotable; se les talaba y se les reducía con quemas que en ocasiones duraban meses, arrasando cientos de hectáreas; la colonización en unos casos menguó y en otros eliminó completamente bosques de robles, laurel, lingue, olivillos y alerces para transformarlos, bien en terrenos agrícolas o para fines agropecuarios (Cornejo, 2015).

Se ha venido hablando hasta aquí de industria pero no se le ha definido. Esta noción en el siglo XIX dista mucho de lo que se entendía por ella en la colonia, o sea, el producto del trabajo agrícola. El historiador Patricio Bernedo (1999), interesado en el estudio de los industriales alemanes de Valdivia, entiende la industria como la persistencia de una o varias de las prácticas frecuentadas en las fábricas de los países metropolitanos, esto es, el uso de maquinaria, la centralización de la producción en un solo lugar, la puesta en práctica del principio de la división del trabajo, el pago de salarios en dinero y su inclinación al mercado, o sea, al lucro. Aunque por razones metodológicas Bernedo se centra en los grandes industriales, no hay que desestimar las empresas comerciales más pequeñas, en términos de productividad y capital, pues ellas también tuvieron su cuota de participación en la reactivación de la economía regional (Quezada, 2009), siendo estas fábricas las que destacan en el envío de objetos que hace el Intendente Irarrázaval a la capital aunque dicho encargo no significó necesariamente su inclusión en el evento ni en la competencia.

Tal como lo proyectabaVicente Pérez Rosales en sus memorias respecto al desarrollo de las arcillas, para 1872 varios directores y dueños de fábricas de ladrillos enviaron a Santiago vía Intendencia cajones con muestras de tejas, diferentes clases de ladrillos y otros 
trabajos de alfarería: Cristóbal Schellhas, Federico Höll, Federico Hettich y Juan de Dios Köning, estos dos últimos premiados con una medalla de bronce por sus ladrillos para chimeneas y con una medalla de plata por un cajón de tejas planas, respectivamente. Junto a esta clase de industria, otros trabajos que colindan con las técnicas manuales merecieron el reconocimiento del jurado: Gustavo Zinke envió varias obras en pelo y obtuvo una mención honrosa; Enrique Werckmeister consiguió una medalla de plata con un costurero fabricado con 20 clases de madera de Valdivia (además de remitir otra colección de 16 muestras de maderas) y Francisco Teodoro Schrader y Cía. quien con un cajón de cola fina obtuvo una medalla de bronce, todos estos trabajos presentados a la Sección II de la exposición. Para la Sección III, Luis Deppe presentó atados de crin para usos industriales, Horacio Pinto Agüero hizo lo propio con la Sección IV presentando un gran tronco fosilizado, lo mismo que Jerónimo Agüero quien para esta sección envió algunas muestras de carbón extraídas de un yacimiento explotado por una sociedad comercial de la que hacía parte junto a otro exponente, Otto Muhm (Quezada, 2009). Finalmente, un par de grupos autodenominados "Varios alemanes de Valdivia" y "Un N.N de Valdivia" enviaron diez tipos de papas, tres clases de corteza de lingue, laurel aromático y ulmo, y otros tres de corteza de canelo, nahuan (¿quizá lahual o alerce?) y tineo o palo santo, grupo que cerraba el cuadro de los proponentes finalmente aceptados en la muestra en el ámbito de la industria. Por el contrario, así como los ya citados Roessell y Pausenberg con sus aguardientes y suelas, que no fueron admitidos en la muestra final, otras colecciones corrieron la misma suerte: dos ganchos para colgar ropa presentados por Emilio Torrer (Torres quizá por error de tipografia), un modelo de fragata de propiedad de Augusto Durbahn, una muestra de cola de Ernesto Frick y "Una colección de animales disecados, que comprende 10 aves y 2 cuadrupedos, entre esto va un didelfhis elegans notable por encontrarse solo en Valdivia" de propiedad de Augusto Hess (El Ferrocarril, 29/8/1872).

La relevancia dada a las muestras de maderas, frente a otras colecciones se podría explicar a partir de la valorización del bosque como recurso comercial dictada por el Estado a principios de la década de 1870. El catálogo de la exposición señalaba al respecto que "Apreciando en su justo valor el gran interés que el cultivo de los bosques acaba de despertar en el país, no se omitido empeño alguno para que esta parte de la Exposicion Agrícola fuese tan completa e instructiva como desearse pueda" (Exposición Nacional de Artes e Industria, 1872, p. 69), haciendo parte de esa valorización la vulgarización y la enseñanza sobre los recursos madereros en el país. Es por ello que junto a las colecciones de maderas se podía encontrar una descripción detallada de ellas extraída de un libro publicado por Benjamín Vicuña Mackenna.

En el ámbito de la industria agrícola valdiviana se envió en representación de la provincia muestras de cebada, harina, granos, cera, miel y algunos capullos de gusanos de seda, últimos que en definitiva no fueron aceptados en el certamen. Carlos Bischofhausen despachó al encuentro cereales y leguminosas obteniendo una medalla de bronce por sus cebadas, lentejas y arvejas, mientras que a Carlos Hofmann se le otorgó una mención honrosa por su harina de centeno y una medalla de bronce por su colección de papas y 
granos. En la misma sección participó el ya citado Otto Muhm quien, junto al ingeniero y profesor de alemán del Liceo de Valdivia Augusto Eisendecher, envió miel de abejas y cera, mientras que José Miguel Portales e Ignacio Agüero mandaron a Santiago linaza blanca y quínoa y linaza común, respectivamente.

\section{El Arte y la ciencia}

Como se ha dicho, entre los colonos arribaron comerciantes, artesanos, agricultores e intelectuales, último grupo que si bien no llegó con un capital financiero apreciable en comparación con los primeros, sí contribuyó a diversificar el espectro cultural de la provincia y del país. Guillermo Frick y Rodulfo Amando Philippi, además de ser personajes paradigmáticos a este respecto, participaron activamente en la Exposición de Artes e Industria de 1872, en parte con colecciones y trabajos personales, así como con otros acervos institucionales bajo su cuidado. Philippi es un caso que bien representa, por así decirlo, la diáspora germana en su vertiente intelectual, pues varios otros alemanes de esta estirpe circularon por las Américas participando activamente en la vida cultural de los países receptores, y más específicamente, en la creación y desarrollo de colecciones, museos y exposiciones en tanto que manifestaciones visibles de un ideal de progreso científico. Este perfil estaría conformado entonces por una formación académica particular a lo que se le suma una fuerte vertiente vocacional interesada en el develamiento de la historia natural.

En el marco de la revolución alemana de 1848-1849 y renunciando al cargo de director del liceo técnico de Cassel que se le había ofrecido a cambio de no migrar, Philippi zarpó desde el puerto de Hamburgo con destino a Valparaíso el 20 de julio de 1851. Ya en Chile se hizo cargo sin mayor éxito de la hacienda que había adquirido su hermano Bernardo y ocupó el cargo de segundo rector del liceo literario de Valdivia, que abandonó al poco tiempo, pues el mismo Andrés Bello le ofreció la cátedra de ciencias naturales en la Universidad de Chile, mientras que el gobierno hacía lo mismo con la dirección del Museo Nacional en 1853, cargo que ocupó hasta 1897 y en el que se destacó por la notoria ampliación de sus colecciones (Schell, 2009; Philippi, 1908). Philippi no solo hizo parte de la Comisión Directiva de la exposición en su cargo de vicepresidente luego que renunciara Mariano Astaburuaga al puesto, sino que también presidió la Sección II de Industria Fabril. Desde su puesto de Director del Museo Nacional de Chile, envió a la exposición un conjunto de plantas medicinales reseñadas con sus nombres vulgar y científico, así como muestras de espigas de trigo de Valdivia. Desconocemos si la totalidad de las colecciones enviadas a su nombre pertenecen al acervo del museo o son realmente de su colección particular. Seguramente, lo que sí hizo parte de su colección personal fue "Un palacio en relieve de tres pisos i cuatro frentes construido en madera por el Padre Lacunsa" que presentó al grupo segundo de la Sección I de Bellas Artes (Exposición Nacional de Arte e Industria, 1872, p. 26). 
Durante su residencia en Valdivia, Philippi tuvo la oportunidad de conocer al abogado y músico Guillermo Frick y al cervecero Carlos Anwandter. Frick, a decir del historiador Gabriel Guarda (1990), el más chileno de los alemanes, zarpó de Bremen a fines de 1839, llegando a Valparaíso los primeros días de enero de 1840. Al abandonar a su familia y su carrera de abogado, Frick representa a los ojos del musicólogo Izquierdo (2008), el ideal de una inmigración desgermanizada que se aculturizaba rápidamente, aunque dicha afirmación tiene que matizarse ya que los esfuerzos de la comunidad de habla alemana por mantener su filiación lingüística y cultural en Chile son innegables y son temas que han mantenido ocupados a los historiadores nacionales en los últimos años (Gänger, 2011).

Después de permanecer un tiempo entre Valparaíso y Santiago, Frick viajó al sur para asentarse en Valdivia, donde conoció a Bernardo, el menor de los Philippi, quien a mediados de la década de 1840 exploraba la provincia en búsqueda de algunos lugares para el asentamiento de futuros de colonos. A partir de 1848 y hasta 1853, cuando se fundó el Club Alemán deValdivia, Frick ocupó de manera sucesiva el cargo de ingeniero en la Junta Provincial de Caminos, el de Agente de Colonización en reemplazo de Pérez Rosales y el de Jefe de la Comisión de Ingenieros responsable de los trabajos del trazado de caminos de la provincia. Sin embargo, sus empeños siempre estuvieron puestos en colaborar con el club, fuera como director del coro mixto de 50 voces, componiendo piezas musicales para orquesta, canto y piano, o incluso como músico, labor que desempeñó especialmente entre 1855 y 1860. Sin dejar de lado sus labores ingenieriles, Frick compuso alrededor de 150 obras musicales y, entre otras cosas, fue también el creador de una de las más valiosas colecciones de árboles y plantas del sur de Chile, cuyas muestras reposaron en el Museo Nacional.

Las bases del concurso de música exigían la remisión de las partituras participantes con seudónimo y en un sobre sellado, de manera tal de mantener la independencia de las decisiones del jurado; de ahí que en la remisión que hiciera Irarrázaval a Vicuña Mackenna se enviara una composición musical etiquetada como N. N. Es probable que esa obra correspondiera a una composición para piano de Guillermo Frick intitulada Polonesa por la cual se le concedió la medalla de plata del concurso. Aunque el catálogo no lo consigna, las memorias del evento lo apuntan también como merecedor de una mención honrosa por su obra Himno a los vencedores del Maipo. En el marco de este mismo concurso, Benjamín Vicuña Mackenna informaba al directorio de la exposición que había recibido una misiva de un tal señor Fonck de Valdivia en la que anunciaba que enviaría varias composiciones musicales para el evento, sin embargo, ese envío y su dueño no aparecen consignados en el catálogo final del evento. Aunque no se podría criticar mucho esta ausencia. Fonck fue uno de los primeros médicos que se desempeñó en la zona y además de cumplir sus funciones oficiales, se ocupó de ordenar taxonómicamente las especies naturales de la provincia y de realizar estudios etnográficos de la población local, fungiendo también como corresponsal en la zona del director del Museo Nacional en Santiago. 
Cuando Philippi aceptó el cargo de director del museo, las colecciones en general eran escasas (Philippi,1908), aumentando de manera notable mientras el intelectual alemán se mantuvo en él, especialmente las relacionadas con la historia natural circundante a Valdivia, zona que llegó a ser una de las mejor conocidas y representadas en el museo. En este caso, el maestro de escuela y reconocido botánico Germán Krause y los médicos Carlos Martin y Francisco Fonck contribuyeron a cristalizar las colecciones de historia natural, que incluían acervos de antropología, geología, zoología y botánica, lo cual deja entrever que la formación de colecciones no era para ese momento una tarea solitaria de un director de museo o de científicos y coleccionistas diletantes, sino que fue una empresa colectiva basada en redes de donantes, informantes y aficionados (Gänger, 2011). Fonck, quien formó parte de la agitación política germana de 1848, llegó a Chile seis años después para desempeñarse como médico de colonia en la zona de Llanquihue, sin embargo, su interés por la geografía y por el estudio de los restos materiales de los pueblos indígenas le llevó a emprender viajes de exploración por la zona, de cuyos resultados conformó colecciones de artefactos nativos y de historia natural, a partir de las cuales escribió una serie de ensayos que compartió con las diferentes sociedades científicas de las que hizo parte dictando algunas conferencias para estas mismas. Además de remitir ejemplares de botánica y zoología al Museo Nacional en Santiago, la colección de artefactos prehistóricos que Fonck reunió durante sus rondas médicas y exploraciones por Llanquihue, fue exhibida en la Exposición del Centenario realizada en Santiago en 1910, lo mismo que las colecciones de arqueología formadas por su sucesor en el cargo de médico, Carlos Martin, que fueron expuestas en las exposiciones internacionales de Santiago (1875) y de Filadelfia (1876), las cuales fueron disueltas y destinadas posteriormente al museo en Santiago y a un par más en la ciudad de Berlín (Gänger, 2011).

En la misma sección de bellas artes, esta vez desde el grupo quinto dedicado a las artes liberales aplicadas a la industria, pruebas fotográficas, litográficas, trabajos de encuadernación, etc. Federico Schrebler presentó varios trabajos de encuadernación y pasta de libros con los cuales se hizo merecedor de una medalla de plata.

Además del aporte realizado en el ámbito de la formación de colecciones, es importante destacar la participación de la colonia teutona en la burocracia departamental, ejerciendo distintos oficios de responsabilidad no menor: desde la planificación y ejecución de obras públicas hasta el ámbito de la salud, pasando por la educación, lo que según Quezada (2009), se explica en virtud de los conocimientos de algunos de sus miembros en materias administrativas, técnicas e intelectuales. Por otro lado, cabe destacar su rol en la ocupación de la así llamada "Araucanía libre", antiguas tierras pertenecientes a los huilliches en donde los puestos de avanzada de algunos colonos de Valdivia y Llanquihue, resultaban puertos secos para científicos y funcionarios interesados en explorar y ocupar esas tierras ancestrales (Gänger, 2011).

Si hubiera que realizar un análisis de las cualidades de las colecciones enviadas por la provincia de Valdivia y otras del norte y extremo norte (Coquimbo y Atacama, respectivamente), del centro (como la del Maule) y del extremo sur (Chiloé y la colonia 
en Magallanes), destacaría la deValdivia, pues es la que se preocupó por enviar, en términos comparativos, más productos manufacturados y otros destinados a su procesamiento, como es el caso de las semillas para la extracción de aceites comestibles o industriales.

Por otro lado, y en contraposición a los productores y hacendados chilenos de la zona central, región más benigna en términos climáticos y de calidad de suelos, la participación activa de industriales y particulares alemanes de la provincia de Valdivia en la exposición podría interpretarse de varias maneras: por un lado, el conocimiento previo que pudieron tener de este tipo de eventos en sus lugares de origen les permitía vislumbrar la exposición de 1872 como un espacio para la escenificación pública del avance civilizatorio teutón en la zona. Por otro, y en ese mismo sentido, era una manera de integrarse y contribuir a construir un ideal de nación del cual también se sentían partícipes, y esto era así ya que Chile los había recibido cuando, en unos casos más que otros, estaban siendo presas de persecución política por su participación en la crisis de 1848, o bien se encontraban agobiados por apremios económicos (Gänger, 2011). Aunque también pudieron haber estado motivados a participar por fines más prosaicos, como el de apuntalar sus productos en el mercado nacional.

Respecto a la negativa de participar por parte de los "hacendados progresistas" (Robles, 2002) de la zona central, además de las variables climáticas y temporales esgrimidas como impedimento, podría haber detrás de ellas otras de tipo político, sobre todo cuando se piensa que fue en el marco de un gobierno liberal cuando se desarrollaron esta y otras exposiciones similares, y en la zona central de Talca y sus alrededores donde se concentró la oligarquía conservadora (Sánchez, 1992).

La participación de la provincia de Valdivia y de otras tantas no pasó desapercibida para los jueces ni para los organizadores de la Exposición de Artes e Industria; los primeros premiaron con una medalla de plata la intervención de la colonia de Magallanes por su "colección de productos de ese territorio" (Exposición Nacional de Artes e Industria, 1873, p. LVI), mientras que la organización decidió asignar un local especial tanto a Valdivia como a Magallanes "como un estímulo a aquellas provincias que, a pesar de hallarse tan apartadas, sabían comprender la utilidad nacional y provincial de estas fiestas industriales” (La República, 30/8/1872).

\section{Reflexiones finales}

El relato sobre la fundación deValdivia reconstruye un aspecto que tiene que ver con la población local antes del arribo de los colonos, lo que nos permite preguntarnos sobre su representación en el evento de septiembre de 1872, en especial de la así denominada gente menuda, entiéndase campesinos e indígenas, incluso pueblo urbano. Al examinar los nombres propios en lengua española de los participantes, se obtiene que de un universo total estimado de 39 exponentes, el 15,38\% tenía apellidos de origen español, seguramente pertenecientes a alguna pequeña élite local, tal como lo demuestra el caso de Jerónimo 
Agüero, más que a la gente menuda que estudia Muñoz. Esa ausencia se explicaría en virtud de la política de colonización implementada hacía poco más de veinte años que enfatizaba los silenciamientos históricos producto de un afán civilizatorio que suprimía presencias anteriores con miras a fundar una nueva edad de origen. Si se atienden los estudios históricos que abordan dichos silenciamientos, podemos llegar a comprender algunas de las razones de fondo para invertir tiempo y dinero en la formación de colecciones que representan regiones y poblaciones: si la variable simbólica que justifica el proyecto migratorio alemán es la del progreso, posiblemente no sea sin razón que el énfasis alemán esté en el carácter "industrial” de la producción agrícola regional.

Carácter que en otras provincias adquirirá otras connotaciones, tal como puede ser el caso de la variable simbólica indígena en la construcción de la representación de la provincia de Arauco. Respecto a este asunto, vale la pena detenerse en la particular solicitud que realiza Vicuña Mackenna al gobernador de Lebu, el oficial Gregorio Urrutia, para que se proveyera de objetos y vestimenta indígena, así como de "algunos tipos juveniles de las diferentes razas araucanas de ambos sexos" con el fin de ser presentados en la exhibición (El Independiente, 17/8/1872).

El breve recuento de la historia de la provincia de Valdivia y de su proceso de colonización no hace más que contextualizar una colección de estirpe provincial, que en el evento de Santiago, adquiere ribetes nacionales. No hay que olvidar que por los años en que se realizaba la exposición el proyecto nacional chileno se encontraba todavía en gestación; baste decir que para ese mismo periodo no se había realizado una exposición de historia nacional propiamente tal, muestra que bajo los auspicios deVicuña Mackenna se realizaría al año siguiente, también en el contexto de las fiestas patrias. En este sentido, el aporte que realizaban tanto chilenos como alemanes con sus objetos se dirigía a apuntalar esa noción en construcción, aporte germano que a mediados de la segunda parte del siglo XIX sería criticado de buena gana sobre todo a partir de influencia que fue adquiriendo tanto en el ámbito educativo como intelectual, lo que se llegó a conocer como "el embrujamiento alemán".

El estudio de la formación de colecciones permite conocer las nociones que subyacen a los esfuerzos por poner en circulación pública una determinada idea a través de la exhibición de objetos. En este sentido, coinciden en dicho estudio a lo menos dos tendencias historiográficas, una historia intelectual que se ocupa por conocer el lugar social de producción del discurso y la historia social, que se encarga de la circulación y recepción del mismo. Esa relación binaria se observa desde la perspectiva museológica, o lo que es lo mismo, desde el estudio crítico de las operaciones museográficas, cuando se realiza la pregunta acerca de quién establece los principios fundantes de una exposición. En este caso, se habla de la racionalidad intelectual del museo que, sobre un manto de aparente armonía, negocia y pacta entre políticos y directivos, los contenidos de una exhibición. No obstante, dicha racionalidad se erosiona en las salas de exposición dando cuenta de la irracionalidad de su mensaje, pues es en ellas en donde las distintas comunidades interpretativas deconstruyen lo que en apariencia ya estaba bien establecido, apropiándose 
del mensaje según sus múltiples imaginarios. He allí la riqueza y las potencialidades del estudio de las colecciones y el coleccionismo.

\section{BIBLIOGRAFÍA}

\section{Fuentes hemerográficas}

Diario El Ferrocarril

Diario El Independiente

Diario La República

\section{Fuentes primarias}

ANGUITA, Ricardo; QUESNEY, Valerio. Leyes promulgadas en chile desde 1810 hasta 1901 inclusive. Santiago: Imprenta Nacional, 1902.

EXPOSICIÓN NACIONAL DE ARTES E INDUSTRIA. Catálogo General. Santiago: Imprenta de la Librería del Mercurio de Orestes L. Tornero, 1872.

Memorias premiadas en el certamen y documentos que les sirven de antecedente. Santiago: Imprenta de la República de Jacinto Núñez, 1873.

PÉREZ,Vicente. Memorias sobre colonización de la provincia de Valdivia.Valparaíso: Imprenta del Diario, 1852.

PHILIPPI, Rodulfo Amando. Historia del Museo Nacional de Chile. Boletín del Museo Nacional de Chile, v.1, n.1, p. 3-30, 1908.

\section{Fuente secundaria}

ACHIM, Miruna. Los años de prueba. La historia inédita de un origen. In: SABORIT, Antonio; ZAREBSKA, Carla (eds.). Museo Nacional de Antropología. 50 aniversarios. Barcelona: Edicions de L’Eixample, 2014.

BENNETT, Tony. The Exhibitionary Complex. New Formations, n. 4, 1988, p. 73-102.

BAUDRILLARD, Jean. El sistema de los objetos. México D.F: Siglo XXI Editores, 1995.

BERNEDO, Patricio. Los industriales alemanes de Valdivia 1850-1914. Historia, v.32, p. 5-42, 1999.

CORNEJO, Roberto. La destrucción del bosque nativo en Chile. Sustainability, Agri, Food and Environmental Research, 3(2), p. 30-32, 2015.

FABA, Paulina. Agencias inesperadas: La museificación del pasado colonial en el Chile del siglo XIX. Atenea, n. 512, p. 137-151, 2015.

GÄNGER, Stefanie. Colecciones y estudios de historia natural en las colonias alemanas de Llanquihue y Valdivia, c. 1853-1910. Historia 396, n.1, p.77-102, 2011.

GUARDA, Gabriel. Guillermo Frick, el más chileno de los alemanes. Boletín de la Academia Chilena de la Historia. v. 57, p. $453,1990$.

HERNÁNDEZ, Carmen. Chile a fines del siglo XIX: exposiciones, museos y la construcción del arte nacional. In: ANDERMAN, Jens; GONZÁLEZ, Beatriz (ed.) Galerías del progreso. Museos, exposiciones y cultura visual en América Latina. Rosario: Beatriz Viterbo Editora, 2006.

IZQUIERDO, José Manuel. Cuando el río suena. Una historia de la música en Valdivia (1840-1970).Valdivia: Fondo CONARTE-Corporación Cultural Municipal de Valdivia, 2008. 
MUÑOZ, Jorge. Políticas centrales, inmigración alemana y gente menuda en la frontera decimonónica.Valdivia, La Unión y Osorno (1840-1890). Revista de Historia Social y de las Mentalidades, v.2, n. 12, p. 23-51, 2008.

MORALES, Luis. Invención de la curiosidad moderna y el museo/paradigma. In:TORRES SEPTIÉN,Valentina (ed.) Producciones de sentido 2.Algunos conceptos de historia cultural. México D.F: Universidad Iberoamericana, 2006.

De la historia cultural como objeto-signo. In: TORRES SEPTIÉN, Valentina (ed.) Producciones de sentido. El uso de las fuentes en la historia. México D.F: Universidad Iberoamericana, 2002.

La invención de la colección museográfica en la producción de significado. Historia y Grafia, n. 15, p. 151-180, 2000.

NISBET, Robert. Historia de la idea de progreso. Barcelona: Editorial Gedisa, 1991.

ORTEGA, Luis. Chile en ruta al capitalismo. Cambio, euforia y depresión 1850-1880. Santiago: Centro de Investigaciones Barros Arana-LOM Ediciones, 2005.

POMIAN, Krzysztof. The Collection: between the visible and the invisible. In: PEARSE, Susan (ed). Interpreting Objects and Collections. Londres: Routledge, 1994.

Historia cultural, historia de los semióforos. In: RIOUX, Jean-Pierre; SIRINELLI, Jean François (ed.) Para una historia cultural. México D.F: Editorial Taurus, 1999.

PHILIPPI, Rodulfo. El orden prodigioso del mundo natural. Rudolph Amandus Philippi. Santiago: Pehuén EditoresUniversidad Austral de Chile, 2004.

QUEZADA, Carlos. Orígenes de la industrialización en Valdivia: inmigración alemana, geografía y resurgimiento económico. Revista de Humanidades, v.19-20, p.119-143, 2009.

ROBLES, Claudio. Modernización Agraria en el Chile del Siglo XIX. Los "Hacendados Progresistas" y La Exposición Nacional de Agricultura de 1869. Iberoamerican Museum of Visual Culture, Disponible en: http://www. bbk.ac.uk/ibamuseum/texts/Robles01.htm. Consultado en: 15 oct. 2017, 2002.

SÁNCHEZ, Raúl. Talca: medio siglo de oligarquía (1850-1900). Universum, 1992. Disponible en: http:// universum.utalca.cl/contenido/index-92/Raul_Sanchez_Andaur.pdf. Consultado en: 10 oct. 2017, 1992.

SCHELL, Patience. Museos, exposiciones y la muestra de lo chileno en el siglo XIX. In: CID, Luis; SAN FRANCISCO, Alejandro (eds.), Nación y nacionalismo en Chile. Siglo XIX. v.1.Santiago: Centro de Estudios Bicentenario, 2009. 


\title{
Museographic reflections of a colonizing politics: the province of Valdivia at the Exhibition of Arts and Industry of Chile Santiago, 1872
}

\begin{abstract}
With two objectives in mind, the article analyzes the collection that the province of Valdivia sent to the Exhibición de Artes e Industria made in Santiago de Chile in 1872. First, it tries to demonstrate that it was the effects of the colonization policy that allowed a differentiation between the collections sent by this province and others exhibited by its peers from the center, north and south end of the country. On the other hand, it is said that, although it is a collection that can represent the civilizing project of a local economic, industrial and intellectual elite, in the scenario of the Santiago exhibition, it is transformed into a nationalist project that contributes to the consolidation of a common imaginary.
\end{abstract}

Keywords: German colonization, science, industry, art, collection.

\section{Reflexões museográficas de uma política colonizadora: a província de Valdivia na Exposição de Artes e Indústria de Santiago do Chile, 1872}

\section{Resumo}

Com dois objetivos em mente, o artigo analisa a coleção que a província de Valdivia enviou à Exposición de Artes e Indústria feita em Santiago do Chile em 1872. Em primeiro lugar, tenta demonstrar quais foram os efeitos da política de colonização que permitiu uma diferenciação entre as coleções enviadas por esta província e outras exibidas por seus pares do centro, norte e extremo sul do país. Por outro lado, afirma-se que, embora seja uma coleção que possa representar o projeto civilizador de uma elite econômica, industrial e intelectual local, no cenário da exposição de Santiago, ela se transmuta para um projeto nacionalista que contribui para a consolidação de um imaginário comum.

Palavras-chave: Colonização alemã, ciência, indústria, arte, coleção. 